Revista Destaques Acadêmicos, Lajeado, v. 8, n. 4, 2016. ISSN 2176-3070 DOI: http://dx.doi.org/10.22410/issn.2176-3070.v8i4a2016.1210 www.univates.br/revistas

\title{
A SOCIEDADE DA INFORMAÇÃO E OS AVANÇOS TECNOLÓGICOS COMO INSTRUMENTOS NO COMBATE À CORRUPÇÃO
}

\author{
Mara Ahlert ${ }^{1}$, Edson Moacir Ahlert ${ }^{2}$
}

\begin{abstract}
Resumo: O artigo aborda a possibilidade de enfrentamento da corrupção através do uso de tecnologias disponíveis na sociedade da informação. O objetivo deste estudo está embasado na pesquisa doutrinária sobre o fenômeno da corrupção e a busca por uma solução para ao menos reduzir a incidência da corrupção na administração pública a nível municipal, estadual e federal. Inicialmente o enfoque será tratar acerca das transformações que as novas tecnologias causam na vida das pessoas, visto que a era digital está presente continuamente no cotidiano dos cidadãos. Posteriormente, será abordado o tema corrupção como fenômeno multidisciplinar, para posteriormente aprofundar a pesquisa analisando se as tendências globais no enfrentamento da corrupção incluem a viabilidade do uso de aplicativos e programas informatizados para o controle social das contas públicas, bem como, se a transparência pode ser uma ferramenta eficaz ao combate da corrupção que assola nosso país.
\end{abstract}

Palavras-chave: Administração pública. Corrupção. Tecnologia da informação.

\section{INTRODUÇÃO}

O tema sob análise tem por finalidade analisar se o uso das tecnologias da sociedade da informação podem ser instrumentos eficazes no combate às práticas corruptivas que ocorrem no Brasil.

Há de se ter claro que a era digital vigente no mundo globalizado faz com que as pessoas estejam conectadas entre si e com o mundo. Além disso, a velocidade no compartilhamento de informações depende de apenas um clique na tela de um computador ou de um celular que esteja conectado à Internet.

É certo que a população atual vive uma nova realidade tecnológica, embasada nas tecnologias de informação e comunicação (TIC), baseada em

1 Bacharel em Direito, professora da Univates. E-mail: mahlert@univates.br.

2 Mestre em Ambiente e Desenvolvimento, professor da Univates. E-mail: edsonahlert@univates.br. 
redes. Estas novas tecnologias são usadas em todos os segmentos que possamos imaginar, incluindo as ferramentas voltadas às informações e compartilhamento de dados nas administrações públicas, através da divulgação eletrônica de suas ações, ou seja, a transparência destas informações.

Em consonância com o tema que envolve os avanços tecnológicos será abordada a corrupção, pois este é um assunto iminentemente presente no cotidiano das pessoas, quer pela sua relevância e materialidade, quer pelo aumento da percepção de sua ocorrência, principalmente em decorrência da propagação das informações por meio das ferramentas de comunicação atualmente disponíveis, as quais são velozes e alcançam todas as classes sociais.

O objetivo deste artigo é tratar da corrupção, bem como, analisar se as tecnologias disponíveis conseguem de alguma maneira efetivar o combate a práticas corruptivas que ocorrem nos mais diversos segmentos dos setores públicos.

É sabido que a corrupção tem se difundido para diversas áreas, havendo comportamentos corruptivos cada vez mais presentes nas instituições públicas, privadas e nas relações sociais.

Desta forma, o desvio sistemático de recursos públicos que seriam aplicados na melhoria da sociedade condena não só as cidades, mas também o país ao subdesenvolvimento econômico e social crônicos. Por isso o combate à corrupção nas administrações públicas deve ser um compromisso de todas as pessoas que se preocupam com o desenvolvimento social e querem construir um país melhor para si e seus filhos.

Por fim, o estudo aponta a necessidade de um controle institucional na busca ao combate da corrupção, a fim de que a prática da corrupção perpetrada por agentes públicos cujo interesse privado se sobrepõe ao interesse público seja punido.

Empregou-se o método dedutivo para direcionar a pesquisa documental e bibliográfica sobre o direito ao acesso à informação pública, assim como para compreender de que modo as medidas utilizadas para combater à corrupção podem ser auxiliadas pelas tecnologias da informação.

Na seção seguinte são apresentados os impactos das novas tecnologias na vida das pessoas. Em seguida, procura-se tratar de corrupção e suas diversas faces e formas de atuação e, a partir daí, concatenar a utilização das tecnologias da informação como ferramenta definidora de estratégias para o caso em questão.

\section{OS IMPACTOS DAS NOVAS TECNOLOGIAS NA VIDA DAS PESSOAS}

As novas tecnologias disponíveis trouxeram consigo uma realidade para a qual muitas pessoas não estavam preparadas, pois os avanços 
tecnológicos na sociedade da informação são muito recentes e sofrem alterações constantemente, pois quando o indivíduo acredita ter dominado o uso de determinada ferramenta tecnológica a mesma já está obsoleta.

Portanto, educar para a nova realidade social desencadeada pela sociedade da informação deve ser uma ação que envolva família, sociedade e Estado.

Esta nova realidade social denominada sociedade da informação, traz a lume uma série de fatos nunca antes vistos, como por exemplo, uma economia com novas regras e formas de fazer negócios virtuais, uma educação que não exige mais a presença física do aluno em sala de aula. Estas transformações têm influência direta na vida das pessoas, gerando inclusive, injustiças sociais, ou "desinclusão digital".

Este novo modelo de organização das sociedades assenta num modo de desenvolvimento social e econômico onde a informação, como meio de criação de conhecimento, desempenha um papel fundamental na produção de riqueza e na contribuição para o bem-estar e qualidade de vida dos cidadãos.

A condição para a Sociedade da Informação avançar é a possibilidade de todos poderem aceder às Tecnologias de Informação e Comunicação, presentes no nosso cotidiano que constituem instrumentos indispensáveis às comunicações pessoais, de trabalho e de lazer.

Conforme assinala Lisboa (2006), com o advento da sociedade da informação as consequências do acesso facilitado à informação invadem todos os meios de comunicação, e não apenas no meio virtual.

Assim como no passado a revolução industrial não suplantou os outros sistemas de produção de bens e sua distribuição (agricultura, pecuária, extrativismo e o comércio), a revolução informacional não acabou com a transmissão de informação por outros meios, como a escrita impressa. Ambas as revoluções incidiram sobre todas as relações sociais, transformando o mundo. Todavia, toda a revolução não significa a superação total da revolução anterior, ao contrário: uma é decorrência da outra e ocorre de forma não linear.

Segundo Lisboa (2006) a expressão sociedade da informação pode ser definida como uma época de intensas transformações que tem ligação direta com a área da informática e abrange também o estudo das relações jurídicas vinculadas aos mais variados meios de comunicação. Resumidamente, a sociedade da informação tem atuação em um ambiente informacional sem ser necessariamente informatizado.

A sociedade da informação representa uma categoria formada pelo conjunto de relações que se estabelecem na contemporaneidade, podendo-se citar cultura, economia, política e espaço público. Segundo Castells (2005), a expressão mais adequada deveria ser sociedade em rede, isto porque para o autor as expressões sociedade da informação e sociedade do conhecimento 
não conseguem descrever a nova realidade, pois informação e conhecimento sempre foram e sempre serão centrais em qualquer sociedade.

Para o autor, a sociedade em rede está baseada na apropriação da Internet com seus usos aliados pelo sistema capitalista. É "uma estrutura social baseada em redes operadas por tecnologias de comunicação e informação fundamentadas na microelectrónica e em redes digitais de computadores que geram, processam e distribuem informação a partir do conhecimento acumulado nos nós dessas redes" (CASTELLS, 2005, p. 20).

Diante dessa nova realidade, muito se tem falado acerca de um suposto isolamento social, colapso da comunicação social e da vida familiar causados pela difusão da Internet. De acordo com Castells (2003), uma análise mais complexa e apurada sobre o uso da Internet desmistificou tais argumentos, demonstrando que o uso da Internet não revolucionou a vida cotidiana em geral.

Castells (2003) refere que se a Internet não cria um padrão de individualismo, por outro lado, ela favorece seu desenvolvimento e dá suporte material apropriado para a propagação do individualismo em rede como uma forma de sociabilidade. Não se pode esquecer, no entanto, que o individualismo é um padrão social e que os indivíduos montam suas redes de contato (on-line ou off-line) de acordo com seus interesses, afinidades e valores.

A prática do individualismo em rede, segundo Castells (2003), pode estar redefinindo as fronteiras de instituições tradicionais como a família, em evidente ganho sob o aspecto individual, no entanto, como bem distingue o autor, com reflexos obscuros sobre a sociedade, a menos que se considere a formação de uma nova forma de sociedade: a sociedade de rede.

Adverte Trivinho (2012) que o espaço público nos anos de 1984, muita coisa mudou com o advento do ciberespaço, pois a partir de então os meios de comunicação estatais e privados cederam lugar a um vasto contingente de possibilidades de comunicação e informação. Diante deste novo cenário está em foco a pessoa comum, a qual pode expressar livremente seu pensamento.

Estas novas tecnologias estão sendo aplicadas também pelo poder público, especialmente pelas administrações públicas, com o intuito de manter um maior controle sobre a gestão e a aplicação de verbas públicas, através de sistemas informatizados que possibilitam a confrontação de dados lançados em rede.

Atualmente, observa-se que a tecnologia pode ser utilizada para encarar o controle das práticas corruptivas, através de uma maior transparência dos dados que anteriormente não eram divulgados em rede.

No entanto, é sabido que o enfrentamento à corrupção no Brasil faz pouco uso das potencialidades das redes sociais nem de outros elementos da tecnologia atual relacionados à participação social. 
Assim, para dar continuidade ao estudo, o capítulo seguinte irá tratar sobre a corrupção e suas diversas faces e formas de atuação.

\section{A CORRUPÇÃO COMO FENÔMENO MULTIDISCIPLINAR}

Conforme esclarece Guaglia (2007), a corrupção perpassa a história da sociedade humana, independente de época ou região, razão pela qual é possível afirmar que é um fenômeno universal e que tem se intensificado com o aumento dos fluxos de pessoas, capital e informação, facilitado pelos avanços tecnológicos.

A corrupção é um tema que pode ser relacionado com diversas áreas, podendo ser citada a sociologia, a história, a filosofia, a política, a ética, o direito, motivo pelo qual é considerada como um fenômeno multidisciplinar.

A corrupção, enquanto ato humano contrário à lei, interessa ao Direito, e este, enquanto fato social, interessa à Sociologia. Logo, especificamente, a matéria enfocada é tema pertinente à Sociologia do Direito, já que, conforme Oliveira (1984), um dos objetivos é buscar uma melhor articulação do direito com a realidade social.

Martins (2000, p. 33) refere que para que haja a compreensão do fenômeno da corrupção é necessário recorrer-se ao auxílio da Sociologia, pois, afinal de contas, é esse o ramo do conhecimento humano que se envolve nos seguintes termos:

Nos debates entre classes sociais, nas disputas e nos antagonismos que ocorriam no interior da sociedade, buscando explicações que sempre contiveram intenções práticas, desejo de intervir no rumo da civilização, tanto para manter como para alterar os fundamentos que a impulsionam e a tornaram possível.

O fenômeno corrupção é conhecido e praticado há séculos e constitui um problema social, político e institucional, o qual contamina ou, em algumas situações, forma relações sociais.

A corrupção pode ser descrita como sendo um fenômeno cultural, legado da colonização portuguesa, que gera uma ética perversa e, infelizmente, consentida e cultuada, fundada com base na esperteza, na ganância, na hipocrisia, na exploração e na fraude, em detrimento do cidadão correto e honesto.

Em relação ao assunto, não há como não se admitir que a corrupção em um país esteja intimamente ligada a fatores como a cultura e a educação de sua população. Podemos citar o Brasil, no qual tem-se um estado de anomia social.

Observando esse ponto, Caminha (2003, texto digital) afirma que no Brasil, a cultura da corrupção deve ter nascido ou sido difundida pela classe dos "homens públicos", que são os políticos, os servidores e administradores 
públicos, os quais, de forma tranquila desrespeitam a legislação e praticam sucessivos atos de improbidade administrativa diante dos olhos de uma sociedade que não vê a punição destes indivíduos na esfera administrativa, nem na esfera judicial (criminal ou civil).

Klitgaard (1994, p. 123), salienta que as práticas corruptivas são um problema de grau e extensão, pois encontra variação no tempo e no espaço. E diz mais:

A experiência mostra que ela pode ser reduzida, se nunca eliminada; e que a maioria dos atos corruptos não são crimes de paixão, mas crimes calculados. Funcionários públicos não são corruptos todo o tempo, mas em cada oportunidade, de modo que é razoável afirmar que um funcionário pratica uma ação corrupta quando, a seu juízo, ela lhe proporcionará mais benefícios do que custos.

Klitgaard (1994, p. 123) aponta como uma das soluções aos praticantes da corrupção, uma punição mais severa, nos seguintes termos:

A escolha da pena poderia ser adotada com olhos voltados para a "cultura de corrupção". Quando a corrupção é sistemática, cinismo e alienação são a regra. Assim, continua o autor, "o sucesso com campanhas anticorrupção sugerem que a pena severa em um "peixe grande" é um modo de começar a subverter aquela cultura. Esse "peixe grande" deve ser um homem público importante, não devendo a punição denotar jogo político.

Pereira (2014) define a corrupção de uma forma bem sucinta e clara, referindo que a prática corruptiva tem haver com o desvio de comportamento de uma pessoa que exerce a função pública, porém com interesses pessoais ou de grupos, violando regras que orientam certos tipos de comportamentos. Além disso, refere que a prática corruptiva também ocorre para melhorar o status e obter alguma vantagem em decorrência do cargo que exerce.

Observando os apontamentos referidos acima, é possível afirmar que a corrupção é um mal social, impregnado na cultura das pessoas. No Brasil, a corrupção se caracteriza pela troca de favores e pelo tratamento privilegiado dos investidores nas decisões que envolvem fundos e políticas públicas, pelos crescentes custos e pelo financiamento privado das campanhas eleitorais, sobretudo por poderosos grupos econômicos que possuem interesses particulares nos resultados das eleições.

Diariamente a mídia nacional divulga em seus noticiários alguma manchete que remeta ao tema da corrupção, o que faz crer acerca da relevância do tema e da necessidade de se aplicar práticas preventivas a este fenômeno.

Diante dessa realidade verifica-se que as patologias corruptivas ocorrem em todas as esferas do governo por meio de práticas danosas ao interesse 
público, motivo pelo qual é essencial que se ache uma solução para prevenir essa prática com base nos instrumentos de disseminação de informação e transparência pública, fortalecimento das ações de controle e de educação da sociedade.

Nesse sentido, Pereira (2014, p.136) demonstra duas vertentes para a corrupção:

\begin{abstract}
No cenário da corrupção duas vertentes: a primeira é representada pela pequena corrupção, na qual o funcionário público se prevalece de sua posição para cobrar propinas para executar aquela tarefa que é de sua responsabilidade. $\mathrm{O}$ interesse privado aqui é representado pelo funcionário que recebe e pelo cidadão que paga a propina. Os seus custos financeiros, em geral, são irrelevantes. Os reflexos dessa ação ilegal são sentidos no nível de credibilidade da população nas instituições. A grande corrupção, por sua vez, acontece nos processos de licitações e contratos, na fiscalização tributária de grandes empresas, na captura de setores específicos do Estado. Verifica-se, nesse caso, que o interesse privado é representado por empresas ou grupos.
\end{abstract}

Segundo o autor, a corrupção pode ser de menor monta, quando ocorre sob a forma de propina, onde o funcionário público recebe vantagem em troca de algum favor, ou de grande monta, na qual há processos de licitação, contratações entre Administração Pública e grandes empresas que representam o interesse privado (PEREIRA, 2014).

As patologias corruptivas estão inseridas nas estruturas institucionais ineficientes, as quais não possuem um gestor competente que fiscaliza seus subordinados e não evita o desperdício de materiais e mão-de-obra.

A corrupção causa prejuízos imensuráveis, pois a mesma pode prejudicar o crescimento econômico de uma nação, afugentando novos investidores diante da incerteza instaurada em um país.

Segundo recente estudo divulgado pela organização Transparência Internacional, que analisou 168 países e territórios, o Brasil é o $76^{\circ}$ colocado em ranking sobre a percepção de corrupção no mundo (TRANSPARENCY INTERNACIONAL, 2015).

A Transparência Internacional é referência mundial na análise da corrupção. O relatório é elaborado anualmente desde 1995, a partir de diferentes estudos e pesquisas sobre os níveis de percepção da corrupção no setor público de diferentes países. $\mathrm{O}$ mapa da figura abaixo mostra a diferença entre os países em corrupção no setor público. 
Figura 1: Índice de Percepção de Corrupção 2015

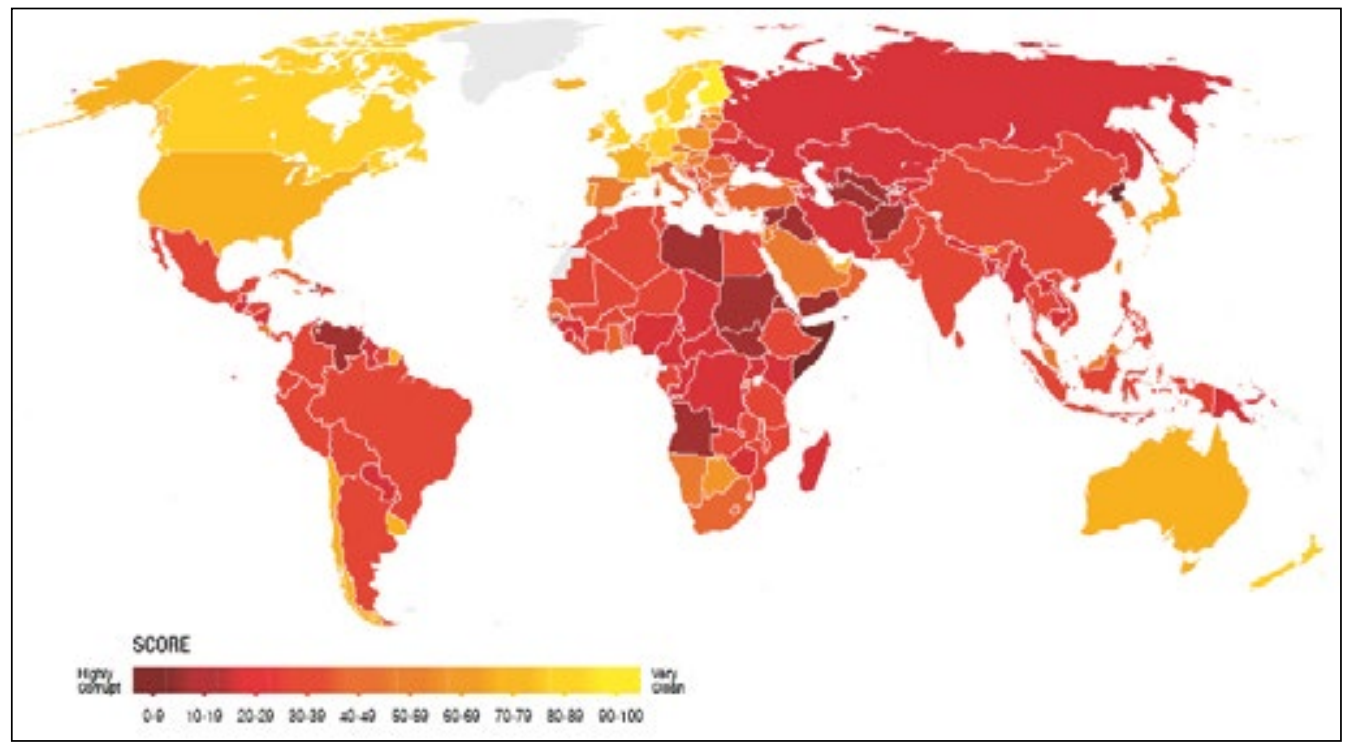

Fonte: Transparency Internacional (2015).

O país perdeu 5 pontos no ranking: tinha 43 pontos em 2014 e ficou com 38 em 2015, ou seja, o país piorou tanto sua posição quanto sua nota. Foi o pior resultado de uma nação no relatório 2015 comparando com o ano anterior (TRANSPARENCY INTERNACIONAL, 2015). A Tabela abaixo mostra a situação do Brasil em relação a América do Sul, com os escores de 2012 a 2015.

Tabela 1: Ranking sobre a percepção de corrupção - Posição Brasil, América do Sul

\begin{tabular}{clcccc}
\hline Rank & Country/territory & $\mathbf{2 0 1 5}$ & $\mathbf{2 0 1 4}$ & $\mathbf{2 0 1 3}$ & $\mathbf{2 0 1 2}$ \\
\hline 21 Uruguai & 74 & 73 & 73 & 72 \\
\hline 23 Chile & 70 & 73 & 71 & 72 \\
\hline $\mathbf{7 6}$ Brasil & $\mathbf{3 8}$ & $\mathbf{4 3}$ & $\mathbf{4 2}$ & $\mathbf{4 3}$ \\
\hline 83 Colômbia & 37 & 37 & 36 & 36 \\
\hline 88 Peru & 36 & 38 & 38 & 38 \\
\hline 99 Bolívia & 34 & 35 & 34 & 34 \\
\hline 107 Argentina & 32 & 34 & 34 & 35 \\
\hline 107 Equador & 32 & 33 & 35 & 32 \\
\hline 130 Paraguai & 27 & 24 & 24 & 25 \\
\hline 158 Venezuela & 17 & 19 & 20 & 19 \\
\hline
\end{tabular}

Fonte: Do autor, com base em Transparency Internacional (2015). 
A organização ressalta que nenhum país do mundo é "livre da corrupção". Em conjunto, mais países avançaram no índice do que caíram de 2014 a 2015 (TRANSPARENCY INTERNACIONAL, 2015).

Assim, urge que se reprima o fenômeno da corrupção que assombra o desenvolvimento do Brasil. É essencial que se promova uma transparência e um controle social dos atos públicos, para garantir o exercício da cidadania através de condutas éticas e sociais, transformando os cidadãos em coautores da construção de um país melhor e mais justo para todos.

\section{A ERA DIGITAL E A TRANSPARÊNCIA COMO INSTRUMENTOS PARA ATENUAR AS PRÁTICAS CORRUPTIVAS NO ÂMBITO DA ADMINISTRAÇÃO PÚBLICA}

O combate à corrupção, controle social e transparência estão interligados entre si, pois com o acesso às informações disponíveis de forma clara sobre o ente público, o cidadão tem a possibilidade de fiscalizar os atos da Administração Pública e estar mais preparado para exercer seu direito de participação na gestão pública.

Há de se considerar que a transparência pode acarretar um aumento do controle social pelos cidadãos, dificultando ou questionando algumas práticas duvidosas que vinham sendo feitas reiteradamente na Administração Pública, tais como a corrupção.

De uma forma bem resumida, este controle social através do acompanhamento eletrônico das ações da Administração Pública, pode ser uma maneira que a sociedade dispõe para fiscalizar a atividade e a gestão do Estado.

Segundo Vieira (texto digital), as atuais instituições não têm condições de garantir a transparência e o controle social pela sociedade civil de forma isolada. É necessário que haja a intervenção dos cidadãos e pressões externas para a tomada de decisões do Poder Público, como a ingerência nos assuntos voltados aos recursos no orçamento público, ou seja, a participação da sociedade nas decisões da Administração Pública.

Algumas cidades já possuem a participação de seus munícipes, onde os cidadãos auxiliam na decisão sobre o destino de parte das verbas para a habitação, por exemplo.

O grande empecilho para que haja a implantação da participação cidadão e a falta de um esclarecimento maior sobre temas voltados a administração pública é a falta de cultura participativa no Brasil.

Havendo uma maior transparência poderá ocorrer o combate à corrupção, sendo garantido o acesso à informação e a possibilidade de ações por parte dos cidadãos contra os vícios que possam existir e até mesmo para promover a participação cidadã que já vem sendo garantida atualmente. 
Bugarin (2003) entende que o controle social em relação aos gastos públicos, não deve ser apenas associado ao marco regulatório como forma de poderem questionar e punir aqueles indivíduos que cometerem crime contra a Administração Pública, e sim possuir uma política consistente e contínua para fortalecer os instrumentos de controle social, participação e transparência com uma fiscalização rigorosa para punir os responsáveis por desvios e atos corruptivos.

É possível constatar que iniciativas de governo eletrônico, que consistem no uso das tecnologias da informação - além do conhecimento nos processos internos de governo - e na entrega dos produtos e serviços do Estado tanto aos cidadãos como à indústria e no uso de ferramentas eletrônicas e tecnologias da informação para aproximar governo e cidadãos, entre eles o portal de transparência, podem ser ferramentas para auxiliar no combate a corrupção na esfera pública.

Se considerarmos como exemplo o Portal da Transparência do Governo Federal, iniciativa da Controladoria-Geral da União (CGU), lançada em novembro de 2004, para assegurar a boa e correta aplicação dos recursos públicos, pode-se observar um aumento significativo em suas estatísticas de acesso, conforme figura abaixo.

Figura 2: Estatísticas de Acesso ao Portal da Transparência da CGU

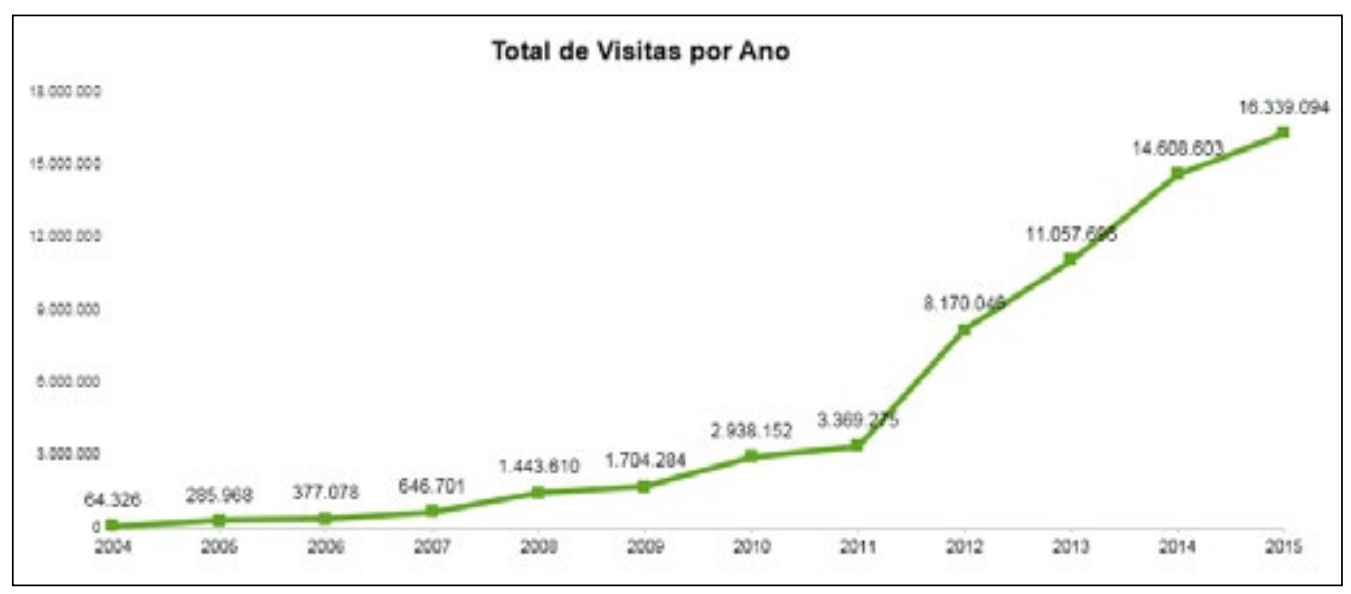

Fonte: Do autor, com base em Portal da Transparência (2016).

Iniciativas como esta mostram que a transparência é o melhor antídoto contra corrupção, dado que ela é mais um mecanismo indutor de que os gestores públicos ajam com responsabilidade e permite que a sociedade, com informações, colabore com o controle das ações de seus governantes, no intuito de checar se os recursos públicos estão sendo usados como deveriam (PORTAL DA TRANSPARÊNCIA, 2016). 
No entanto, merece destaque a preocupação exposta por Lemos (2016), o qual refere que enquanto as relações da sociedade entre si são mediadas pela tecnologia, por meio de redes sociais, dispositivos de comunicação instantânea e os demais avanços característicos desses novos tempos, a relação entre governo, governantes e sociedade ainda é medida pelo aparato da burocracia.

Da mesma forma que as novas tecnologias crescem e avançam em todos os segmentos (agricultura, negócios, educação), é indispensável que estas tecnologias também devam ser utilizadas para o combate às práticas corruptivas, pois cada vez mais os cidadãos possuem garantido em seu favor o acesso a dados informatizados.

\section{CONSIDERAÇÕES FINAIS}

A corrupção é uma mazela social com consequências catastróficas e que precisa ser combatida com muito empenho tanto através de políticas públicas quanto através do controle social. Todavia, é necessário que a sociedade tenha instrumentos aptos e eficientes para que essa luta tenha resultados práticos vantajosos.

A pesquisa demonstra que através do auxílio das tecnologias da informação e comunicação, como a Internet, o combate às práticas corruptivas pode ser potencializado, pois permite uma maior facilidade de acesso aos dados e informações da Administração Pública.

Verificou-se que as TIC são importantes ferramentas para a facilitação do acesso à informação, direito humano fundamental, trazendo, por consequência, perspectivas para a democracia participativa no ambiente digital.

Contudo, para que o potencial democrático proporcionado pela informação e pela transparência governamental não seja desperdiçado no contexto da sociedade informacional, é necessário que o Estado empreenda esforços no sentido de garantir o direito de acesso à informação, bem como direcione suas atividades administrativas para a concretização do princípio da transparência, levando em consideração a importância das TIC e as vantagens trazidas pelas ferramentas e aplicativos online.

No combate à corrupção, a questão da transparência passa a ter um lugar de destaque, visto que a corrupção se apresenta como um fenômeno que enfraquece a democracia, a confiança no Estado, a legitimidade dos governos e a moral pública e nesse sentido é perceptível que o Brasil avançou no acesso à informação, no alcance das investigações, no engajamento popular (tanto nas manifestações de rua como via redes sociais) e no fortalecimento do Poder Judiciário.

Assim, o enfoque principal desta pesquisa se fundamenta no fato de que a estrutura governamental deve se tornar cada vez mais parecida com uma estrutura em rede, sob pena de, não se informatizando, tornar-se cada vez mais 
burocrática e ineficiente, havendo em decorrência disso um aumento de crises de legitimidade.

A divulgação das informações públicas e o uso das tecnologias da informação e comunicação e a Internet são mecanismos facilitadores na busca pela transparência e acesso às informações e documentos governamentais, sendo os principais mecanismos para a transparência e participação social porque expõe as ações do Estado e dos gestores públicos. Dados abertos podem ser cruzados, analisados e gerar novas informações que permitem aos cidadãos exercerem o seu direito de controle social e apoiarem a formulação de políticas públicas mais adequadas e legítimas.

Assim, espera-se que as diversas mudanças no modo de gerir a coisa pública levem a uma utilização em escala cada vez maior dos recursos (de tecnologia e técnicas de gestão da informação e/ou conhecimento) disponíveis na Sociedade da Informação.

\section{REFERÊNCIAS}

ARAÚJO, Luiz Alberto David. Pessoa portadora de deficiência: proteção constitucional das pessoas portadoras de deficiência. 3. ed., rev., ampl. e atual. Brasília: CORDE, 2003.

ARAÚJO, Luiz Alberto David (Coord). Defesa dos direitos das pessoas portadoras de deficiência. São Paulo: Revista dos Tribunais, 2006.

BAHIA, Claudio José Amaral; KOBAYASHI, Wilson. Os direitos da pessoa portadora de deficiência e a necessidade de cumprimento de pena em regime prisional. p.3562. In: ARAUJO, Luiz Alberto David (Coord). Direito da pessoa portadora de deficiência: uma tarefa a ser completada. Baury: EDITE, 2003.

BITTENCOURT, Marcus Vinícius Corrêa. Curso de direito constitucional. Belo Horizonte: Fórum, 2007.

BRASIL. Constituição (1998). Constituição da República Federativa do Brasil: promulgada em 5 de outubro de 1988. Vade Mecum / Editora Saraiva. 13. ed. São Paulo: Saraiva, 2012.

BUGARIN, Maurício Soares. Controle dos gastos públicos no Brasil: instituições oficiais, controle social e um mecanismo para ampliar o envolvimento da sociedade. BUGARIN, Mauricio Soares. VIEIRA, Laércio Mendes. GARCIA, Leice Maria. KonradAdenauer-Stiftung: Rio de Janeiro, 2003.

FÁVERO, Eugênica Augusta Gonzaga. O direito das pessoas com deficiência de acesso à educação, p.152-174. In: ARAUJO, Luiz Alberto David (Coord). Defesa dos direitos das pessoas portadoras de deficiência. São Paulo: Revista dos Tribunais, 2006. 
GORCZEVSKI, Clóvis. Direitos humanos, educação e cidadania: conhecer, educar, praticar. Santa Cruz do Sul: Edunisc, 2009.

LEMOS, Ronaldo; Fabro Steibel e Carlos Affonso Souza. Tecnologia, redes sociais e o combate à corrupção no Brasil. Disponível em: <http:/ / fgvprojetos.fgv.br/sites / fgvprojetos.fgv.br/files/caderno_lei_anticorrupcao_site.pdf>. Acesso em: 21 nov. 2016.

MACHADO, Martha de Toledo. A Proteção Constitucional de Crianças e Adolescentes e os Direitos Humanos. São Paulo: Manole, 2003.

MANDELLI, Mariana. Oito em cada dez das matrículas da educação especial estão em escolas públicas. Publicado em 2012. Disponível em: <http:/ / educacao.uol.com. br/noticias/2012/06/14/oito-em-cada-dez-matriculas-da-educacao-especial-estaoem-escolas-publicas.htm>. Acesso em: 26 out. 2016.

MANTOAN, Maria Teresa Egler. Igualdade e diferença na escola: como andar no fio da navalha. In: MANTOAN, Maria Teresa Egler, PRIETO, Rosângela Gavioli, ARANTES, Valéria Amorim (Org.). Inclusão escolar: pontos e contrapontos. São Paulo: Summus, 2006.

MELLO, Celso Antônio Bandeira de. Conteúdo jurídico do princípio da igualdade. 3. ed. atual., 4. tiragem. São Paulo: Malheiros, 1997.

NEME, Eliana Franco. Dignidade, igualdade e vagas reservadas, p.133-151. In: SILVA, José Afonso da. Curso de direito constitucional positivo. 21. ed. São Paulo: Malheiros, 2003.

OKAMOTO, Gary A. Medicina Física e Reabilitação. São Paulo: Manoele, 1990.

PORTAL DA TRANSPARÊNCIA. Estatísticas de Acesso 2016. Disponível em: <http://www.portaltransparencia.gov.br>. Acesso em: 10 out. 2016.

RIBEIRO, Valéria Cristina Gomes. O direito à inclusão social das pessoas portadoras de deficiência: um caminho para o exercício da democracia. In: Jus Navigandi, Teresina, ano 6, $n^{\circ}$ 53, jan. 2002. Disponível em: <https://jus.com.br/artigos/2546>. Acesso em: 20 out. 2016.

SILVA, Marcelo Amaral da. Digressões acerca do princípio constitucional da igualdade. In: Jus Navigandi, Teresina, ano 7, nº 66, jun. 2003. Disponível em: <http:/ / jus2.uol.com.br/doutrina/texto.asp?id=4143>. Acesso em: 19 out. 2016.

TRANSPARENCY INTERNACIONAL. Corruption Perceptions Index 2015.

Disponível em: <http:/ / www.transparency.org/cpi2015>. Acesso em: 20 nov. 2016.

VIEIRA, Liszt. Cidadania e Sociedade Civil no Espaço Público Democrático.

Disponível em: <http:/ / empreende.org.br/pdf/Capital Social e Cidadania/

Cidadania e sociedade civil no espaço público democratico.pdf $>$. Acesso em: 22 nov. 2016. 